\title{
Adubação nitrogenada, potássica e fosfatada influenciando a qualidade e durabilidade pós-colheita de gladíolo ${ }^{(1)}$
}

\author{
ROSANGELA JULIANA MARQUES ROSA (2); YARA BRITO CHAIM JARDIM ROSA (2); \\ EDGARD JARDIM ROSA JUNIOR ${ }^{(2)}$; EULENE FRANCISCO SILVA ${ }^{(3)}$; MATHEUS ANDRADE \\ MARTINEZ(2); DEREK BRITO CHAIM JARDIM ROSA (2); JACKELINE SCHULTZ SOARES (2)
}

\begin{abstract}
RESUMO
O gladíolo é uma das flores de corte mais produzidas e comercializadas no Brasil e no mundo. Conduziu-se esse trabalho com o objetivo de avaliar o uso da adubação nitrogenada e potássica associada a diferentes fontes e doses de fósforo na qualidade e durabilidade em pós-colheita de gladíolos (Gladiolus hortulanus L. cv. T704) cultivados em Latossolo Vermelho Distroférrico. Utilizou-se o delineamento experimental em blocos cazualizados e os tratamentos foram arranjados em esquema de parcelas sub-subdivididas. Nas parcelas foram alocadas a presença ou não da adubação nitrogenada e potássica (NK), nas subparcelas as fontes de fósforo (superfosfato triplo, superfosfato simples e farinha de osso) e nas sub-subparcelas as cinco doses de $\mathrm{P}(0,75$, 150,225 e $300 \mathrm{~kg} \mathrm{ha}^{-1}$ ) dos fertilizantes estudados. As plantas foram avaliadas quanto ao número de botões florais, número de botões coloridos, número de flores abertas, qualidade da folha, qualidade da flor, qualidade da haste, altura da planta, comprimento da espiga floral, diâmetro e durabilidade da flor. Independentemente dos tratamentos e das combinações estudadas, as folhas produzidas foram classificadas como ótimas. A ação conjunta dos três fatores estudados $(p<0,05)$ foi observada apenas sobre o diâmetro e a durabilidade das flores. Concluiu-se que a adubação NK é fundamental e que as dosagens utilizadas neste trabalho foram suficientes para a obtenção da classe I de qualidade de gladíolos. A utilização de superfosfato triplo é mais eficiente quando se objetiva durabilidade das flores e, a de superfosfato simples, quando se objetiva qualidade das hastes florais. Doses de fósforo entre 150 e $160 \mathrm{~kg} \mathrm{ha}^{-1}$ são suficientes para obtenção de durabilidade e qualidade das flores e hastes dessa cultivar.
\end{abstract}

Palavras-chaves: Gladiolus hortulanus, floricultura, flores de corte e Latossolo Vermelho Distroférrico.

\begin{abstract}
Influence of nitrogen, potassium and phosphate fertilizers on quality and longevity of gladiolus

The gladiolus is one of the most cut flowers produced and marketed in Brazil and worldwide. This work was conducted with the objective to evaluate the use of nitrogen and potassium fertilization associated with different sources and levels of phosphorus in the quality and durability in postharvest gladiolus (Gladiolus hortulanus L. cv. T704 ) cultured in oxisoil. It was used the experimental design randomized blocks and the treatments were arranged in sub-subplots. The plots were allocated the presence or absence of nitrogen and potassium fertilization (NK), subplots sources of phosphorus (triple superphosphate, superphosphate and bone meal) and the sub-subplot the five P rates $\left(0,75,150,225\right.$ and $\left.300 \mathrm{~kg} \mathrm{ha}^{-1}\right)$ fertilizers studied . Plants were evaluated on the number of flower buds, number of colored buttons, and number of open flowers, leaf quality, and flower quality, quality of the stem, plant height, and length of floral spike, diameter and durability flower. Regardless of treatments and combinations studied, the leaves produced were classified as optimal. The combined action of the three factors studied $(\mathrm{p}<0.05)$ was observed only on the diameter and durability of flowers. It was concluded that NK fertilization is crucial and that the dosages used in this study were sufficient to obtain class I quality gladiolus. The use of triple superphosphate is more efficient when the goal of flowers and

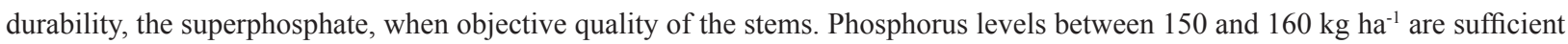
to obtain durability and quality of the flowers and stems of this cultivar.
\end{abstract}

Keywords: Gladiolus hortulanus, floriculture, cut flower and oxisol.

\section{INTRODUÇÃO}

De 2000 a 2008, houve um acréscimo de US\$ 23,53 milhões de dólares nas exportações brasileiras de flores e plantas ornamentais. Em 2010, a exportação de bulbos, rizomas e cormos correspondeu a $46,31 \%$ das exportações do setor, totalizando US\$13,28 milhões, sendo os cormos de gladíolos e os bulbos de amarílis os mais comercializados nesse período (JUNQUEIRA E PEETZ, 2011).
O gladíolo é cultivado mundialmente como flor de corte ou para a produção de cormos (TOMBOLATO, 2004). No Brasil, tornou-se uma cultura de grande expressão devido ao seu ciclo curto (60 a 120 dias) sendo que $70 \%$ da produção de suas hastes florais abastecem o mercado interno enquanto que os cormos são utilizados para replantio da cultura ou para a exportação (RUPPENTHAL E CASTRO, 2005).

Embora se desenvolva bem em diferentes tipos de clima e solo, a produção comercial de gladíolos requer adequada

\footnotetext{
(1) Trabalho recebido para publicação em 26/11/2012 e aprovado em 09/06/2014

(2) Universidade Federal da Grande Dourados - Faculdade de Ciências Agrárias. Rodovia Dourados-Itahum km 12, Dourados-MS. rosangelajmrosa@gmail.com

(3) Universidade Federal Rural do Semi Árido, Departamento de Ciências Ambientais e Tecnológicas. Avenida Francisco Mota, no 572, Bairro Costa e Silva, Mossoró-RN.
} 
disponibilidade de nutrientes tais como nitrogênio, potássio, cálcio, magnésio e fósforo para produção de flores, folhas e cormos de qualidade, uma vez que tanto a deficiência quanto o excesso de nutrientes provocam distúrbios fisiológicos e morfológicos na planta (TOMBOLATO, 2004).

$\mathrm{O}$ nitrogênio $(\mathrm{N})$ é o nutriente mais exigido pelos vegetais e está relacionado a processos fisiológicos entre os quais a fotossíntese, respiração, desenvolvimento e atividade das raízes (TAIZ e ZEIGER, 2009). Em muitos sistemas de produção, a disponibilidade de nitrogênio é quase sempre um fator limitante, influenciando o crescimento da planta mais do que qualquer outro nutriente (FERNANDES, 2006).

O potássio $(\mathrm{K})$ está entre os nutrientes mais exigidos pelos vegetais, pois está envolvido no crescimento meristemático. A absorção e a manutenção de água pela célula e pelos tecidos é frequentemente consequência da absorção ativa desse íon (FERNANDES, 2006).

$\mathrm{O}$ fósforo $(\mathrm{P})$, por sua vez, é requerido para o armazenamento e transferência de energia, fotossíntese, processo de transporte de elétrons, regulação de atividade enzimática na síntese de açúcar e no transporte de carboidrato. Quando há deficiência de fósforo, o crescimento da planta é retardado (FERNANDES, 2006). Na cultura do gladíolo a deficiência de N, K e P causam prejuízo na qualidade das folhas, devido à alteração da sua coloração.

A deficiência de nitrogênio e potássio interfere na qualidade das flores no que se refere ao número de botões e ao comprimento da haste floral (TOMBOLATO, 2004) sendo esses dois quesitos os que mais interferem na classificação das flores produzidas, pois, segundo Bongers (2000), hastes de gladíolos para serem classificadas como extra devem apresentar comprimento superior a $120 \mathrm{~cm}$ e mais de 16 botões florais.

Zubair e Wazir (2007) relatam que o fósforo afeta o tamanho do primeiro botão floral até a identificação da coloração, o tamanho do primeiro botão totalmente aberto e o número de espigas produzidas por cormo.

As fontes de fósforo mais utilizadas são o superfosfato simples (20\% de P2O5), triplo (45\% P2O5) e a farinha de osso (30\% P2O5), sendo os dois primeiros de origem mineral e o terceiro de origem orgânica. O superfosfato triplo, por apresentar maior conteúdo de fósforo disponível que o superfosfato simples, apresenta vantagens econômicas em razão do menor volume a ser adicionado ao solo com consequente redução de custos operacionais como o transporte. A farinha de osso tem a vantagem de ser um produto renovável, embora tenha que ser mineralizada no solo por microorganismos para ser absorvida pela planta (MALAVOLTA, 2006).

A região da Grande Dourados-MS está inserida no bioma do cerrado, que é caracterizado por solos de baixa fertilidade e elevada acidez, necessitando de correção e fertilização, principalmente de N, P e K para estarem aptos à produção de gladíolos, uma vez que o mercado consumidor de flores e plantas ornamentais prioriza qualidade.
Em vista do exposto, este trabalho foi desenvolvido com o objetivo de avaliar o uso da adubação nitrogenada e potássica associada a diferentes fontes e doses de fósforo na qualidade e durabilidade em pós-colheita de gladíolos cultivados em Latossolo Vermelho Distroférrico em Dourados-MS.

\section{MATERIAL E MÉTODOS}

O experimento foi conduzido na área de Jardinocultura da Faculdade de Ciências Agrárias (FCA) da Universidade Federal da Grande Dourados (UFGD) em Dourados-MS, nas coordenadas latitude $22^{\circ} 11^{\prime} 45^{\prime \prime} \mathrm{S}$ e longitude $54^{\circ} 55^{\prime} 18^{\prime \prime} \mathrm{W}$, com altitude de $446 \mathrm{~m}$, de setembro de 2010 a janeiro de 2011. O clima é do tipo Cwa mesotérmico úmido, segundo a classificação de Koppen (1948), a precipitação média anual é de $1500 \mathrm{~mm}$ e as médias máximas e mínimas anuais de temperatura do ar são de 24 e $20{ }^{\circ} \mathrm{C}$, respectivamente.

O solo da área, classificado como Latossolo Vermelho Distroférrico, apresentou os seguintes atributos químicos: $\mathrm{pHCaCl}_{2}=5,19 ; \mathrm{pHH}_{2} \mathrm{O}=6,08 ; \mathrm{P}=6,65 \mathrm{mg} \mathrm{dm}^{-3} ; \mathrm{K}=42,0$ $\mathrm{mg} \mathrm{dm}{ }^{-3} ; \mathrm{Al}=0,10 \mathrm{mmol}_{\mathrm{c}} \mathrm{dm}^{-3} ; \mathrm{Ca}=43 \mathrm{mmol}_{\mathrm{c}} \mathrm{dm}^{-3} ; \mathrm{Mg}=$ $26 \mathrm{mmol}_{\mathrm{c}} \mathrm{dm}^{-3} ; \mathrm{H}+\mathrm{Al}=34,4 \mathrm{mmol}_{\mathrm{c}} \mathrm{dm}^{-3} ; \mathrm{SB}=73,2 \mathrm{mmol}_{\mathrm{c}}$ $\mathrm{dm}^{-3} ; \mathrm{T}=107,6 \mathrm{mmol} \mathrm{dm}^{-3} ; \mathrm{V} \% \stackrel{\mathrm{c}}{=} 68$ e foi corrigido com calcário dolomítico Filler (PRNT de 92\%), 45 dias antes do plantio dos cormos, para obtenção de $80 \%$ de saturação de bases, conforme recomendação de Tombolato (2004).

Os canteiros com 1,00 m de largura por $12,00 \mathrm{~m}$ de comprimento foram levantados com o auxílio de um rotoencanteirador que também incorporou o calcário em uma camada de $30 \mathrm{~cm}$ de profundidade.

Utilizou-se o delineamento experimental blocos casualizados e os tratamentos foram arranjados em esquema de parcelas sub-subdivididas, com quatro repetições, constituídas de cinco plantas cada. Nas parcelas foram alocadas a presença ou a ausência da adubação nitrogenada $\left(80 \mathrm{~kg} \mathrm{ha}^{-1}\right)$ e potássica $\left(150 \mathrm{~kg} \mathrm{ha}^{-1}\right)$, segundo as recomendações de Feltrin (2009) e Rosa et al. (2009). Essas quantidades foram divididas em três parcelas iguais e aplicadas em cobertura no ato do plantio e aos 15 e 40 dias de cultivo. Foi utilizada como fonte de nitrogênio a uréia $(46 \%$ de $\mathrm{N})$ e como fonte de potássio o $\mathrm{KCl}\left(60 \%\right.$ de $\left.\mathrm{K}_{2} \mathrm{O}\right)$.

Nas subparcelas foram alocadas as fontes de fósforo, que se constituíram de superfosfato simples (SFS), superfosfato triplo (SFT) e farinha de osso (FO). As sub-subparcelas foram compostas de cinco doses $(0,75,150,225$ e $300 \mathrm{~kg}$ $\mathrm{ha}^{-1}$ de fósforo) de cada fertilizante estudado.

Como material de estudo foram utilizados cormos de gladíolo (Figura 1A) de tamanho 10/12 (extremos dos perímetros dos cormos) Gladiolus hortulanus L. cv. T704, conhecida como "Lavander", cujas características são: flores de coloração lilás, ciclo de 75 dias, altura da planta entre 90 e $120 \mathrm{~cm}$ e cultivo a pleno sol, podendo ser cultivada o ano todo em climas quentes (Figura 1B). 

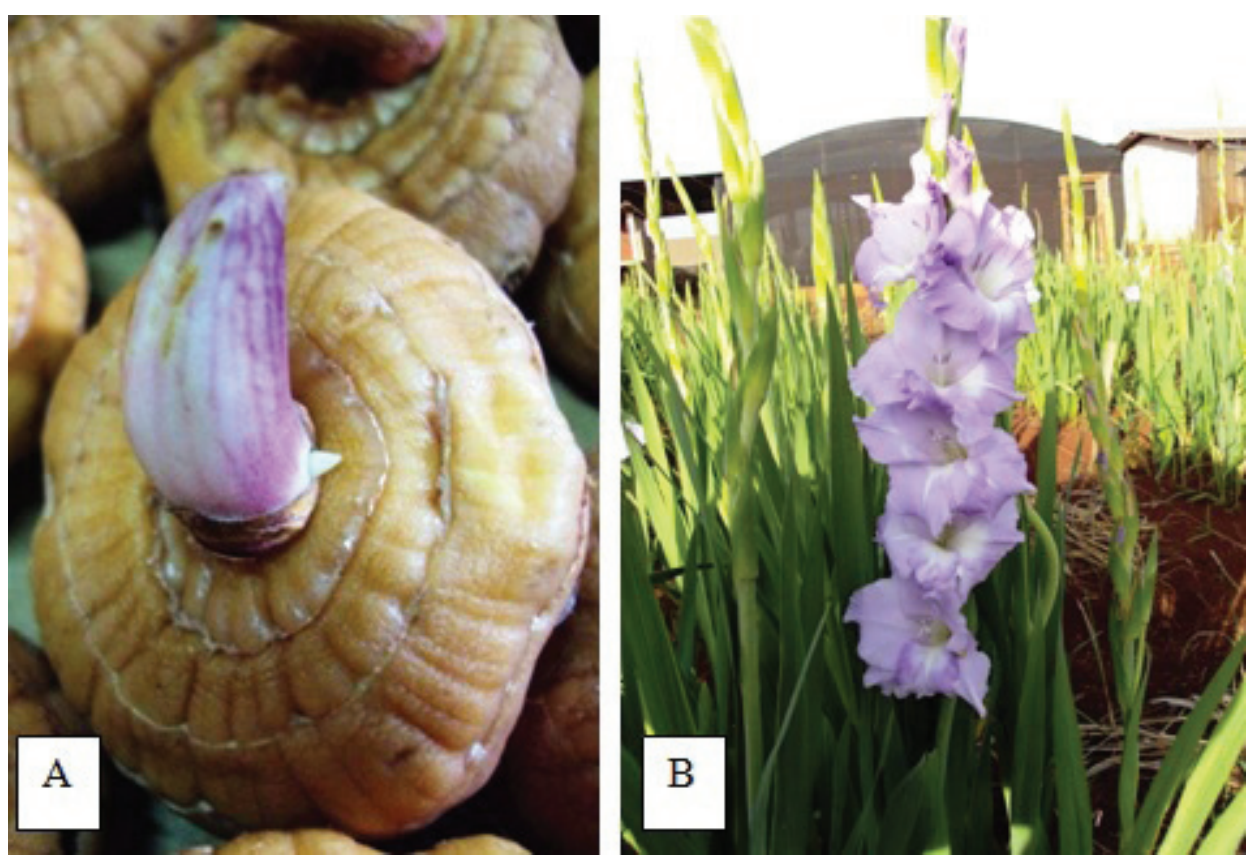

Figura 1. (A) Cormos, (B) planta e inflorescência de Gladiolus hortulanus L. cv. T704. Dourados-MS, UFGD, 2011.

Figure 1. (A) Corms, (B) plant and inflorescence of Gladiolus hortulanus L. cv. T704. Dourados-MS, UFGD 2011.

Os cormos foram tratados com solução Captan ${ }^{\circledR} 5 \%$ segundo as recomendações de Tombolato (2004) e ventilados à sombra. Depois de secos, foram plantados, em canteiros, a $15 \mathrm{~cm}$ de profundidade, em sistema de fileiras simples com espaçamento de $07 \mathrm{~cm}$ na linha e $50 \mathrm{~cm}$ nas entrelinhas. Como tratos culturais foram realizadas capinas manuais semanais nos canteiros e, para o controle de formigas, utilizou-se sulfuramida (isca granulada), três vezes por semana, durante 35 dias após a emergência das plantas.

Durante o período experimental, semanalmente, as plantas receberam uma lâmina de água correspondente a $12 \mathrm{~mm}$, dividido em três aplicações, conforme recomendação de Borges (2005), sendo descontados os volumes da precipitação pluviométrica.

Aos 63 dias após o plantio iniciou-se o processo de colheita (Figura 2A). As plantas que apresentavam quatro botões coloridos foram cortadas rente ao solo e acondicionadas em local sombreado, a base de suas hastes foi submersa em água, para evitar a desidratação (Figura 2B). A seguir, o excesso de folhas foi removido (deixando-se duas folhas por haste) e cada conjunto de haste e folhas foi envolvido individualmente em jornal (Figura 2C), identificado quanto ao tratamento e acondicionado em câmara fria $\left(12 \pm 2{ }^{\circ} \mathrm{C}\right.$; $80 \pm 5 \%$ UR) desprovida de iluminação, em baldes providos de água, onde permaneceu por três dias, sendo a água trocada diariamente.
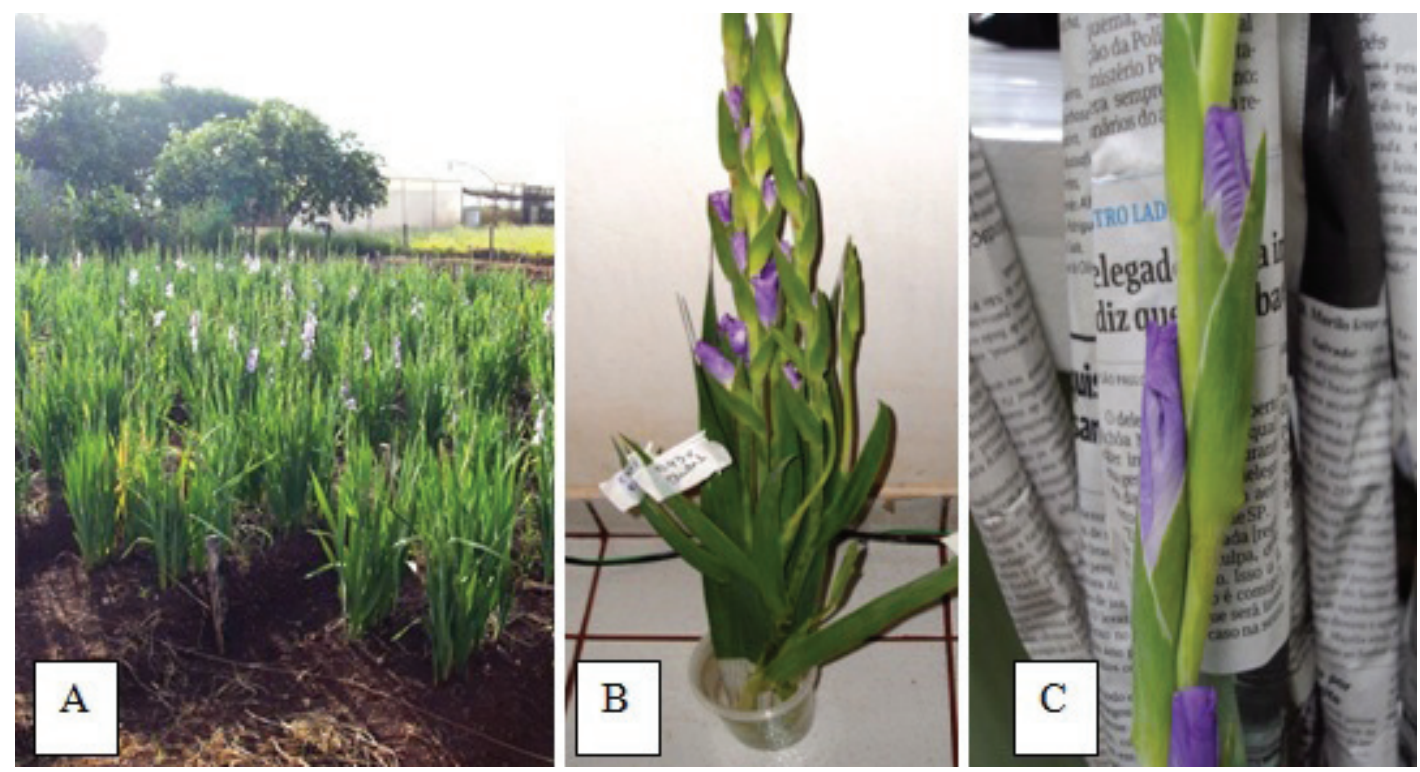

Figura 2. (A) Início da floração; (B) planta colhida com quatro botões coloridos; (C) embalagem das plantas de Gladiolus hortulanus L. cv. T704 em jornal para serem submetidas à refrigeração. Dourados-MS, UFGD, 2011.

Figure 2. (A) Top of flowering, (B) plant take with four colored buttons; (C) packaging of Gladiolus hortulanus L. cv. T704 plant's in newspaper to be subjected to cooling. Dourados-MS, UFGD 2011. 
Após este período, as plantas foram avaliadas quanto ao número de botões coloridos, número total de botões, número de flores abertas, qualidade da folha, qualidade da flor, qualidade da haste, altura da planta (distância, em cm, da base da haste floral até a inserção do botão apical), comprimento da espiga floral (distância, em cm, entre a inserção do botão floral basal e o apical) e diâmetro das flores abertas (medido com o auxílio de um paquímetro digital). Após estas avaliações, as hastes florais foram colocadas em vasos providos de água e mantidas em ambiente com luminosidade e refrigeração similares às condições domésticas $\left(23 \pm 2{ }^{\circ} \mathrm{C} ; 70 \pm 5 \% \mathrm{UR}\right)$.

Diariamente cortou-se um centímetro basal das hastes florais e trocou-se a água dos vasos, sendo avaliada a durabilidade da flor (número de horas para o murchamento do $1^{\circ}$ botão floral basal). Para avaliação da qualidade das flores, foram utilizados os critérios propostos por Bongers (2000) (Tabela 1), e para a avaliação da planta foram feitas adaptações dos critérios propostos por Silva et al. (2008) que estão contidas no Tabela 2.

Tabela 1. Classificação de gladíolos recém-colhidos.

Tabela 2. Classification of newly harvested gladiolus.

\begin{tabular}{c|c|c|} 
Classificação & $\begin{array}{c}\text { Comprimento das } \\
\text { hastes florais }\end{array}$ & $\begin{array}{c}\text { Número de botões } \\
\text { por inflorescência }\end{array}$ \\
Extra & $>120 \mathrm{~cm}$ & $>16$ \\
I & $100-120 \mathrm{~cm}$ & 12 a 16 \\
II & $80-100 \mathrm{~cm}$ & $8 \mathrm{a} 12$ \\
III & $60-80 \mathrm{~cm}$ & $<8$ \\
\hline
\end{tabular}

Os resultados foram submetidos à análise de variância. Os fatores qualitativos, quando significativos, foram comparados por teste de médias até $5 \%$ de probabilidade, sendo utilizado o teste $t$ de Studant para comparar a presença ou ausência da adubação nitrogenada e potássica e o teste de Tukey para comparar as fontes de fósforo. Ao fator quantitativo foram ajustadas curvas de regressão. Para análise estatística utilizouse o aplicativo computacional SISVAR 5.3 (FERREIRA, 2010).

\section{RESULTADOS E DISCUSSÃO}

Independentemente dos tratamentos e das combinações estudadas, as folhas produzidas e avaliadas na pós-colheita apresentaram-se com tonalidade verde vibrante, sem injúrias e manchas, perfeitas para exposição ornamental (Figura 3), recebendo nota 0 (zero) e sendo classificadas como ótimas, conforme a Tabela 2 .

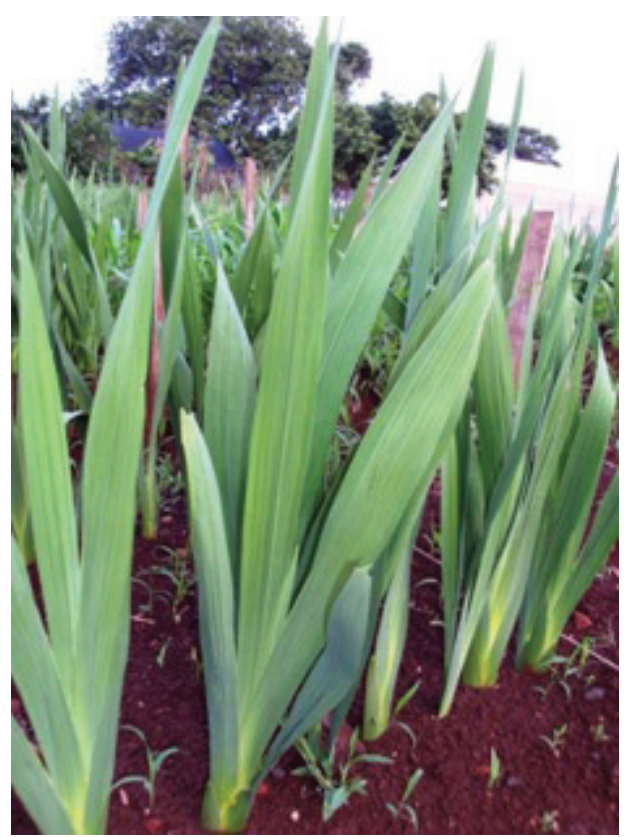

Figura 3. Qualidade das folhas de Gladiolus hortulanus L. cv. T704. Dourados-MS, UFGD, 2011.

Figure 3. Quality of Gladiolus hortulanus L. cv. T704 leaves. Dourados-MS, UFGD 2011.

A tabela 3 apresenta os resumos das análises de variância das demais características de Gladiolus hortulanus L. cv. T704, suas médias gerais e o nível de significância dos fatores estudados.
A ação conjunta dos três fatores estudados foi observada sobre a durabilidade em vaso e diâmetro das flores abertas (Tabela 3). 
Tabela 2. Classificação dos gladíolos na pós-colheita.

Table 2. Classification of gladiolus in postharvest.

\begin{tabular}{|c|c|c|}
\hline Nota & Classificação & Qualidade das flores \\
\hline 1 & Inaceitável & $\begin{array}{c}\text { Senescência completa da flor, murchamento, escurecimento pronunciado das pétalas, } \\
\text { senescência completa das pétalas, haste com escurecimento, imprestável para } \\
\text { comercialização. }\end{array}$ \\
\hline 2 & Inaceitável & $\begin{array}{l}\text { Flores sem murchamento aparente mais com injúrias causadas por lagartas, } \\
\text { inaceitável para comercialização. }\end{array}$ \\
\hline 3 & Ruim & $\begin{array}{l}\text { Murchamento acentuado, presença de manchas nas pétalas e hastes, injúrias } \\
\text { pronunciadas, enrugamento e escurecimento evidente das pétalas. }\end{array}$ \\
\hline 4 & Ruim & $\begin{array}{l}\text { Limite de aceitação da flor quando for observada perda do valor ornamental e } \\
\text { comercial. Flores não vigorosas com murchamento em alguns botões e injúrias. }\end{array}$ \\
\hline 5 & Regular & $\begin{array}{c}\text { Inicio de murchamento, aparência ligeiramente atrativa, com manchas e injúrias e/ou } \\
\text { enrugamento. }\end{array}$ \\
\hline 6 & Regular & $\begin{array}{c}\text { Inicio de murchamento, aparência ligeiramente atrativa, ausência de manchas e } \\
\text { injúrias e/ou enrugamento. }\end{array}$ \\
\hline 7 & Boa & $\begin{array}{c}\text { Flor fresca, turgidas, ligeiro murchamento, com manchas nas sépalas sem injúrias, } \\
\text { ausência de enrugamento. }\end{array}$ \\
\hline 8 & Boa & $\begin{array}{l}\text { Flor fresca, turgidas, isenta de injúrias, muito atrativa, mais com as bordas das } \\
\text { sépalas apresentado manchas. }\end{array}$ \\
\hline 9 & Ótima & $\begin{array}{c}\text { Flor fresca, turgidas, isenta de injúrias, muito atrativa, perfeita para exposição em } \\
\text { vasos. }\end{array}$ \\
\hline Nota & Classificação & Qualidade das folhas \\
\hline 0 & Ótima & $\begin{array}{l}\text { Folhagem aparentemente perfeita, verde vibrante, sem injúrias e manchas. Perfeita } \\
\text { para exposição ornamental. }\end{array}$ \\
\hline 1 & Regular & $\begin{array}{l}\text { Folhas com tonalidade verde, mas com injúrias causadas por lagarta, mas com } \\
\text { ausência de manchas. }\end{array}$ \\
\hline 3 & Inaceitável & Folhagem com injúrias feitas por lagartas com manchas e tonalidade verde opaco. \\
\hline Nota & Classificação & Qualidade das hastes florais \\
\hline 0 & Ótima & $\begin{array}{l}\text { Haste ereta perfeita para comercialização e exposição ornamental, sem injúrias e } \\
\text { manchas. }\end{array}$ \\
\hline 1 & Regular & Haste ligeiramente torta. \\
\hline 3 & Inaceitável & Haste torta de uso não comercial. \\
\hline
\end{tabular}

Fonte: Silva et al.,2008.

O maior valor de durabilidade (3,5 dias) foi obtido com a utilização de adubação NK associada com a dose calculada de $158,8 \mathrm{~kg} \mathrm{ha}^{-1}$ de fósforo, tendo como fonte o superfosfato triplo (SFT) (Figura 4E).

Independentemente das doses de fósforo utilizadas, a aplicação isolada de SFT (Figura 4F) e a combinação de NK + farinha de osso (FO) (Figura 4A) não afetaram a durabilidade das flores, sendo que a combinação NK + FO propiciou cerca de 5 horas a mais de durabilidade que a aplicação isolada de SFT.

A utilização de superfosfato simples (SFS) na ausência de NK propiciou decréscimos na durabilidade à medida que as doses de fósforo foram aumentadas (Figura 4D). $\mathrm{Na}$ ausência da aplicação de SFS, a durabilidade calculada foi de 2,8 dias, igual à média observada com a aplicação de NK + FO (Figura 4A). Com a utilização de $300 \mathrm{~kg} \mathrm{ha}^{-1}$ de fósforo (FO), a durabilidade calculada foi de 2,0 dias, valor este $43 \%$ inferior ao máximo observado com a utilização de $158,8 \mathrm{~kg}$ $\mathrm{ha}^{-1}$ de fósforo (SFT).

De acordo com Malavolta et al. (1997) e Mascarenhas et al.(2000), a aplicação de altas doses de cálcio pode provocar desequilíbrio nutricional nas plantas, evidenciando o efeito antagônico do $\mathrm{Ca}^{2+}$ (contido nas fontes de fósforo utilizadas) em relação à absorção, tanto do $\mathrm{K}^{+}$quanto do $\mathrm{Mg}^{2+}$, visto que todos são nutrientes catiônicos que competem fortemente pelos mesmos sítios de absorção.

$\mathrm{O}$ teor de $\mathrm{K}^{+}$encontrado no solo de cultivo foi de $0,42 \mathrm{mg}$ $\mathrm{dm}^{-3}$, valor este que, segundo Tombolato (2004), necessitaria de uma adição de $100 \mathrm{~kg} \mathrm{ha}^{-1}$ de $\mathrm{K}_{2} \mathrm{O}$. Portanto, a redução da durabilidade em vaso pode ser atribuída à adição continuada de SFS e FO sem a devida suplementação de $\mathrm{K}^{+}$, uma vez que este regula o potencial osmótico das células vegetais e a sua deficiência aumenta a respiração causando o murchamento acelerado dos tecidos vegetais (KERBAUY, 2009; TAIZ e ZEIGER, 2009).

De maneira geral, as flores apresentaram maior diâmetro (média de 106,3mm) quando as plantas receberam adubação nitrogenada-potássica (NK) em conjunto com adução fosfatada em doses variando de 158 a $197 \mathrm{~kg} \mathrm{ha}^{-1}$ (Figura $5 \mathrm{~A}, \mathrm{C}, \mathrm{E})$.

A ausência de adubação NK propiciou flores com diâmetros de $85,2 \mathrm{~mm}$ (Figura 2B) e de 88,4 (Figura 5D) quando a fonte de fósforo utilizada foi a FO ou SFS, respectivamente. A utilização de SFT na ausência da adubação NK propiciou flores com diâmetro de 98,2 mm na presença de $172,8 \mathrm{~kg} \mathrm{ha}^{-1}$ de fósforo (Figura 5F). 
Tabela 3. Resumo das análises de variância do número de botões coloridos (NBC), número de botões (NB), número de flores abertas (NFA), qualidade da flor (Qflor), qualidade da haste floral (QH), altura da planta (AP), comprimento da haste floral (CH), comprimento da espiga floral (CE), diâmetro da flor (Diflor) e durabilidade das flores (DFlor) de Gladiolus hortulanus L. cv. T704. Dourados-MS, UFGD, 2011.

Table 3. Summary of analyzes of variance of the number of colored buttons (NBC), number of buttons (NB), number of open flowers (NFA), flower quality (Qflor), quality of floral stem (QH), plant height (AP), flower stem length (CH), length of floral spike (CE), flower diameter (Diflor), durability offlowers (DFlor) Gladiolus hortulanus L. cv. T704. Dourados-MS, UFGD 2011.

\begin{tabular}{|c|c|c|c|c|c|c|}
\hline & & \multicolumn{5}{|c|}{ Quadrados médios } \\
\hline F.V. & G.L. & NBC & NB & NFA & QFlor & QH \\
\hline Bloc & 3 & 2,15 & $1,05^{\mathrm{ns}}$ & $0,10^{\text {ns }}$ & $0,28^{\mathrm{ns}}$ & $0,09^{\text {ns }}$ \\
\hline N K & 1 & $1,63^{\mathrm{ns}}$ & $1,40^{\text {ns }}$ & $0,43 *$ & $2,70 * *$ & $1,31 *$ \\
\hline Fonte & 2 & $7,85^{*}$ & $0,45^{\mathrm{ns}}$ & $0,14^{\text {ns }}$ & $0,25^{\mathrm{ns}}$ & $0,12^{\text {ns }}$ \\
\hline N K*Fonte & 2 & $0,90^{\mathrm{ns}}$ & $2,05^{\mathrm{ns}}$ & $0,06^{\mathrm{ns}}$ & $0,52^{\mathrm{ns}}$ & $0,01^{\mathrm{ns}}$ \\
\hline Dose & 4 & $5,75^{*}$ & $4,49 * *$ & $0,02^{\text {ns }}$ & $0,19^{\text {ns }}$ & $0,06^{\mathrm{ns}}$ \\
\hline N K*Dose & 4 & $2,50^{\mathrm{ns}}$ & $2,86^{*}$ & $0,02^{\text {ns }}$ & $0,47^{\mathrm{ns}}$ & $0,08^{\mathrm{ns}}$ \\
\hline Fonte*Dose & 8 & $1,73^{\text {ns }}$ & $2,37^{*}$ & $0,05^{\mathrm{ns}}$ & $0,69^{\text {ns }}$ & $0,12 *$ \\
\hline N K*Fonte*Dose & 8 & $2,06^{\mathrm{ns}}$ & $1,04^{\mathrm{ns}}$ & $0,04^{\mathrm{ns}}$ & $0,42^{\mathrm{ns}}$ & 0,02 \\
\hline Resíduo & 78 & 2,00 & 0,88 & 0,05 & 0,35 & 0,05 \\
\hline $\mathrm{CV}(\%)$ & & 17,71 & 6,70 & 21,29 & 7,42 & 17,14 \\
\hline Média Geral & & 8,0 & 14,1 & 0,3 & 8,0 & 1,1 \\
\hline F.V. & G.L. & $\mathbf{A P}$ & $\mathrm{CH}$ & $\mathrm{CE}$ & DFlor & DiFlor \\
\hline Bloc & 3 & $163,50^{\mathrm{ns}}$ & $60,12^{\text {ns }}$ & $91,17^{\text {ns }}$ & $76,96^{\mathrm{ns}}$ & 15,87 \\
\hline N K & 1 & $426,50^{*}$ & $75,16^{\text {ns }}$ & $143,57^{\text {ns }}$ & $288,22 *$ & $1861,48^{* *}$ \\
\hline Fonte & 2 & $54,81^{\text {ns }}$ & $16,75^{\text {ns }}$ & $64,10^{\text {ns }}$ & $225,27 * *$ & $72,88^{\mathrm{ns}}$ \\
\hline N K*Fonte & 2 & $358,34^{\text {ns }}$ & $51,48^{\mathrm{ns}}$ & $144,26^{\mathrm{ns}}$ & $245,68 * *$ & $9,00^{\text {ns }}$ \\
\hline Dose & 4 & $225,82^{\text {ns }}$ & $109,09^{\text {ns }}$ & $63,58^{\text {ns }}$ & $326,15^{* *}$ & $1577,53 * *$ \\
\hline N K*Dose & 4 & $305,39^{\text {ns }}$ & $103,37^{\mathrm{ns}}$ & $126,64^{* *}$ & $306,69 * *$ & $310,85^{* *}$ \\
\hline Fonte*Dose & 8 & $207,01^{\text {ns }}$ & $107,29^{\text {ns }}$ & $50,33^{\text {ns }}$ & $411,54 * *$ & $48,45^{\text {ns }}$ \\
\hline N K*Fonte*Dose & 8 & $156,14^{\mathrm{ns}}$ & $70,50^{\text {ns }}$ & $45,69^{\text {ns }}$ & $139,34^{*}$ & $239,70 * *$ \\
\hline Resíduo & 78 & 133,03 & 77,27 & 33,68 & 63,36 & 42,05 \\
\hline $\mathrm{CV}(\%)$ & & 10,56 & 15,68 & 10,92 & 11,99 & 7,11 \\
\hline Média Geral & & $109,2 \mathrm{~cm}$ & $56,1 \mathrm{~cm}$ & $53,1 \mathrm{~cm}$ & 2,8 dias & $91,3 \mathrm{~mm}$ \\
\hline
\end{tabular}

** significativo, ao nível de $1 \%$ de probabilidade, pelo teste $\mathrm{F}$

* significativo, ao nível de $5 \%$ de probabilidade, pelo teste $\mathrm{F}$

ns não significativo

O maior diâmetro de flores $(107,3 \mathrm{~mm})$ foi obtido com a utilização de adubação NK associada com a dose calculada de $167,0 \mathrm{~kg} \mathrm{ha}^{-1}$ de fósforo, tendo como fonte o superfosfato simples (SFS) (Figura 5B).

Os resultados observados neste trabalho corroboram com o relato de Zubair (2011) que atribui à adubação nitrogenada o aumento das características de crescimento vegetativo e à adubação potássica o aumento no tamanho das flores de gladíolo.

Efeitos conjuntos da adubação NK e das doses de fósforo foram observados sobre o número de botões florais (Figura 6A) e sobre o comprimento da espiga floral (Figura 6 B).

O maior número de botões florais $(14,6)$ foi obtido com a utilização de adubação NK combinada com $300 \mathrm{~kg} \mathrm{ha}^{-1} \mathrm{de}$ fósforo. $\mathrm{Na}$ ausência de $\mathrm{NK}$, o maior número de botões foi obtido com a dose calculada de $162,5 \mathrm{~kg} \mathrm{ha}^{-1}$ de adubação fosfatada produzindo 14,5 botões (Figura 6A). Os valores obtidos com estas combinações permitiram a classificação das flores como Classe I (12 a 16 botões florais por espigas) conforme o contido na Tabela 1 .

O maior comprimento de espiga $(57,5 \mathrm{~cm})$ foi observado com a utilização de NK combinada com a dose calculada de $178,2 \mathrm{~kg} \mathrm{ha}^{-1}$ de fósforo. A ausência de NK propiciou espigas com comprimento médio de $52,0 \mathrm{~cm}$, independentemente da dose de fósforo utilizada (Figura 6B).

Os resultados obtidos corroboram os relatos de Tombolato (2004) que salienta que tanto o nitrogênio quanto o potássio são responsáveis pelo número de botões florais, sendo o potássio isoladamente responsável pelo comprimento da haste floral.

O número de botões também foi influenciado pela ação conjunta das fontes e das doses de fósforo (Figura 7A), que também atuaram significativamente sobre a qualidade da haste floral (Figura 7B). 

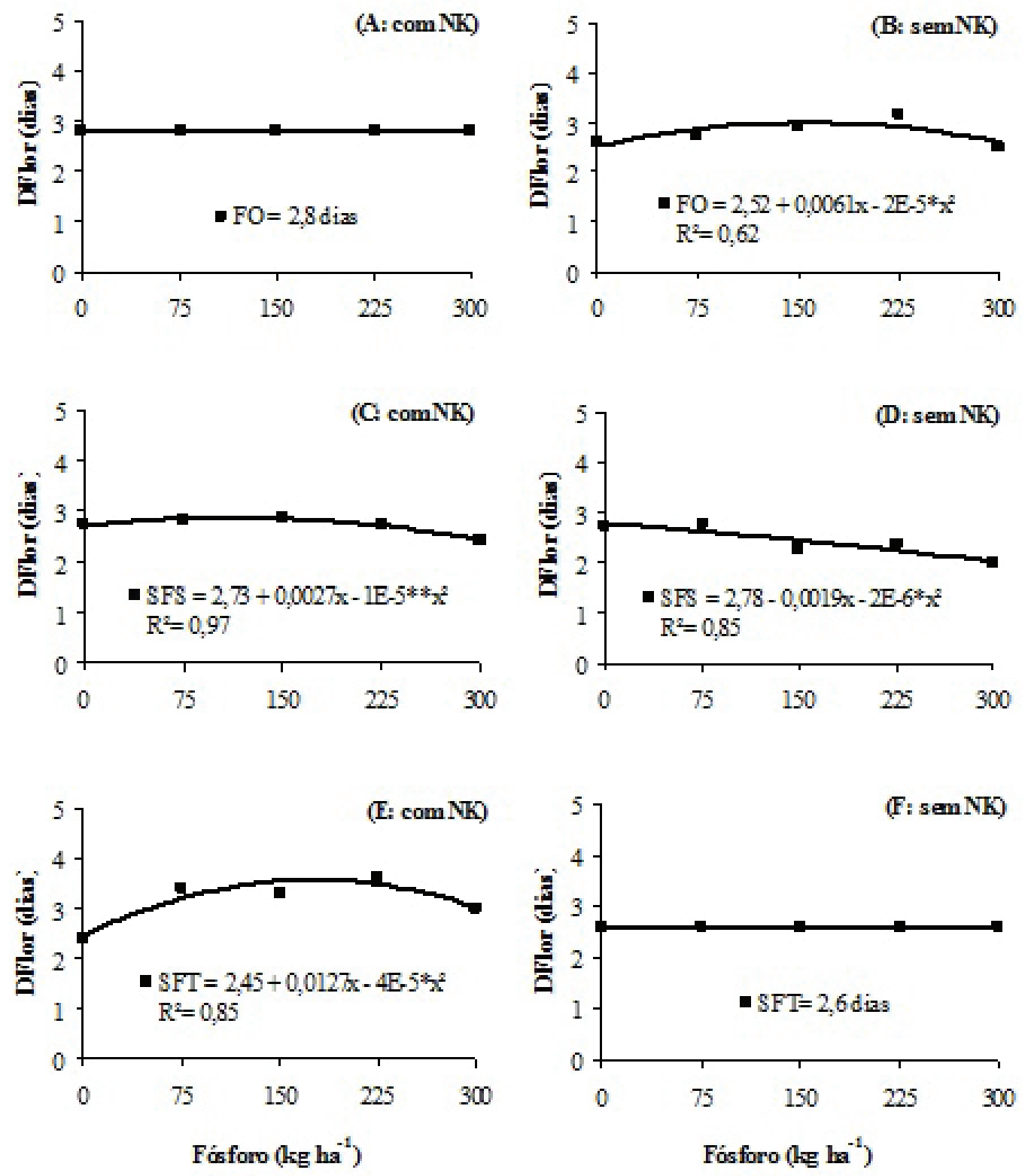

Figura 4. Durabilidade das flores (DFlor) de Gladiolus hortulanus L. cv. T704, na presença (com NK) e ausência (sem NK) da adubação nitogenada-potássica, em função das fontes e das doses de fósforo estudadas. Dourados-MS, UFGD, 2011. (FO= farinha de osso; $\mathrm{SFS}=$ superfosfato simples; $\mathrm{SFT}=$ superfosfato triplo).

Figure 4. Durability of flowers (DFlor) Gladiolus hortulanus L. cv. T704 in the presence (com NK) and absence (sem NK) of nitrogen and potassium fertilization, depending on the sources and levels of phosphorus. Dourados-MS, UFGD 2011. (FO = bone flour; SFS = single superphosphate; TSP = triple superphosphate)

O maior número de botões florais $(14,9)$ foi registrado com a utilização de SFS na dose calculada de $184,2 \mathrm{~kg} \mathrm{ha}^{-1}$ de fósforo, seguido da FO (14,4 botões) com a dose calculada de $181,7 \mathrm{~kg} \mathrm{ha}^{-1}$, enquanto que o SFT, independentemente da dose utilizada, apresentou 13,9 botões por espiga floral (Figura 7A). Estes resultados também permitiram a classificação das flores produzidas como Classe I (12 a 16 botões florais por espigas) conforme a Tabela 1 .

Hastes classificadas como ótimas (nota 0,8 ) foram obtidas com a dose calculada de $152,5 \mathrm{~kg} \mathrm{ha}^{-1}$ de fósforo (SFT) enquanto que a utilização de FO e SFT, independentemente da dose de fósforo aplicada, propiciou hastes classificadas como regulares (nota 1,2), segundo os critérios de avaliação contidos na Tabela 2 (Figura 7B).
O número de botões coloridos obtidos após o processo de refrigeração foi influenciado isoladamente pelas doses (Figura 8A) e pelas fontes (Figura 8B) de fósforo utilizadas. Em relação a esta variável, quanto menor o número de botões coloridos maior será a vida em vaso dessas flores.

O menor número de botões coloridos $(7,2)$ foi observado na ausência da adubação fosfatada, enquanto que a utilização de 222,5 propiciou 8,2 botões coloridos.

O superfosfato simples foi a fonte de fósforo que propiciou o menor número de botões coloridos (Figura $8 \mathrm{~B}$ ), entretanto é importante ressaltar que, após o processo de armazenamento, as plantas apresentaram, em média, três botões coloridos a mais que na época da colheita. 

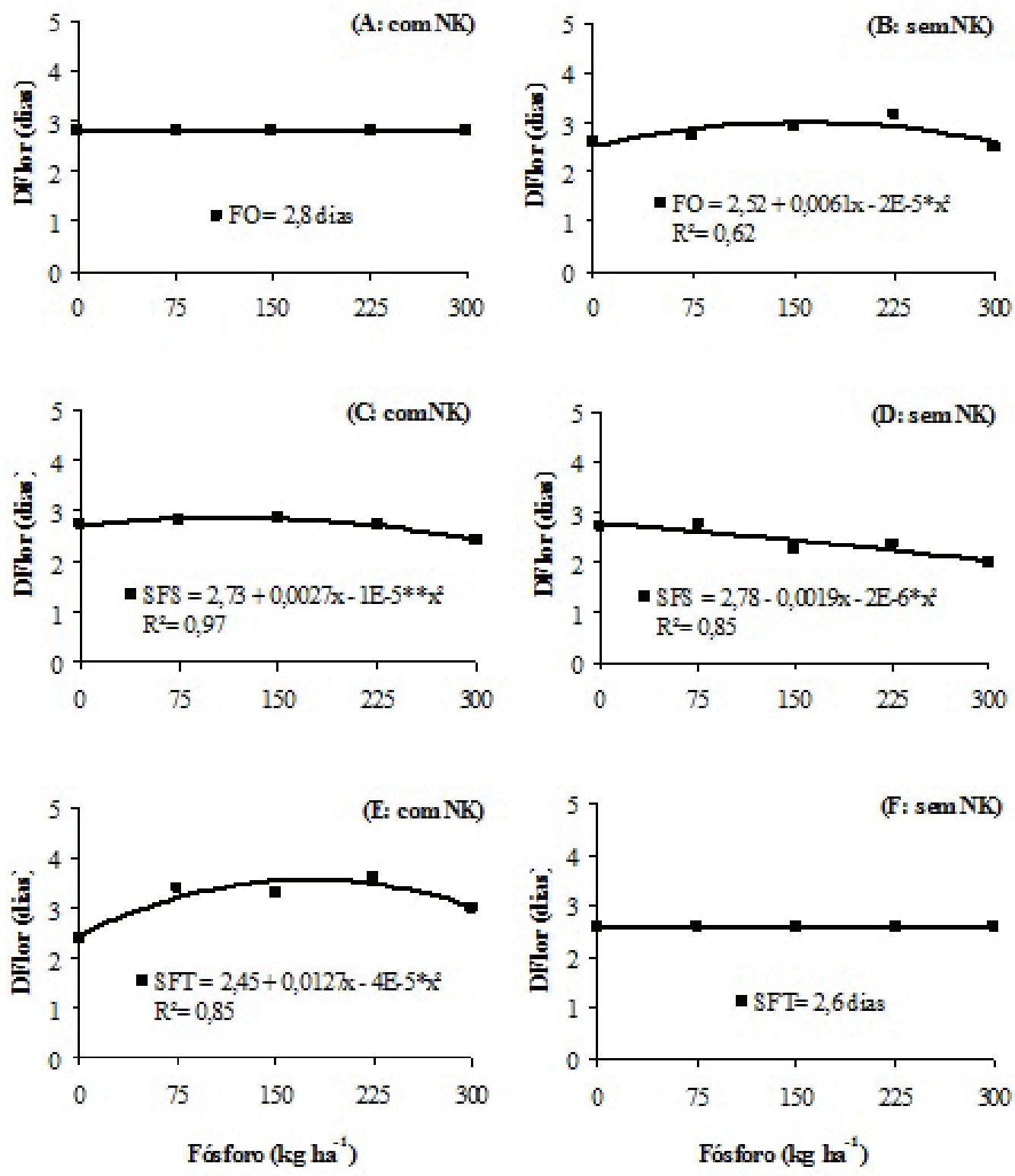

Figura 5. Diâmetro das flores (DiFlor) de Gladiolus hortulanus L. cv. T704, na presença (com NK) e ausência (sem NK) da adubação nitogenada-potássica, em função das fontes e das doses de fósforo estudadas. Dourados-MS, UFGD, 2011. (FO= farinha de osso; SFS= superfosfato simples; $\mathrm{SFT}=$ superfosfato triplo).

Figure 5. Diameter of flowers (DiFlor) of Gladiolus hortulanus L. cv. T704 in the presence (com NK) and absence (sem NK) of nitrogen and potassium fertilization, depending on the sources and levels of phosphorus. Dourados-MS, UFGD 2011. (FO = bone meal; SFS = single superphosphate; TSP = triple superphosphate).

Estes resultados são interessantes quando as hastes florais forem utilizadas imediatamente após o processo de refrigeração, entretanto isso irá reduzir o tempo de vida em vaso.

Efeitos isolados da adubação nitrogenada e potássica foram observados sobre o número de flores abertas, qualidade da flor, qualidade da haste floral e altura das plantas (Tabela 3). Para estas variáveis, a utilização de NK propiciou melhores resultados do que o cultivo sem adição destes nutrientes. Com a utilização de adubação NK, as hastes submetidas a póscolheita apresentaram número de flores abertas igual a 0,2; qualidade de flores igual a 8,2; qualidade de haste floral igual a 0,8 e altura das hastes iguais a $1,1 \mathrm{~m}$, valores estes superiores estatisticamente àqueles observados sem a adição de NK $(0,5$; 7,9; 1,4 e 1,0 m, respectivamente) (Figura 9).
Em relação ao número de flores abertas, quanto menor o número, melhor será a qualidade da haste e sua expectativa de vida em vaso, uma vez que a durabilidade média dos botões florais desta variedade é de 2,8 dias (Tabela 3) e se abrem da base para o ápice da espiga floral. As flores foram classificadas como boas (Tabela 2) independentemente do uso de NK, entretanto as flores produzidas com NK apresentaram-se túrgidas enquanto que as outras com leve murchamento. Estes resultados podem ser explicados pela ação do potássio que é responsável pelo turgor celular (TAIZ e ZEIGER, 2009).

As plantas produzidas com NK apresentaram qualidade de haste floral classificadas como boas e sem NK como regulares (Tabela 1). Em relação à altura, as plantas foram classificadas na classe I (hastes entre 100 e $120 \mathrm{~cm}$ ), segundo Bongers (2000), 

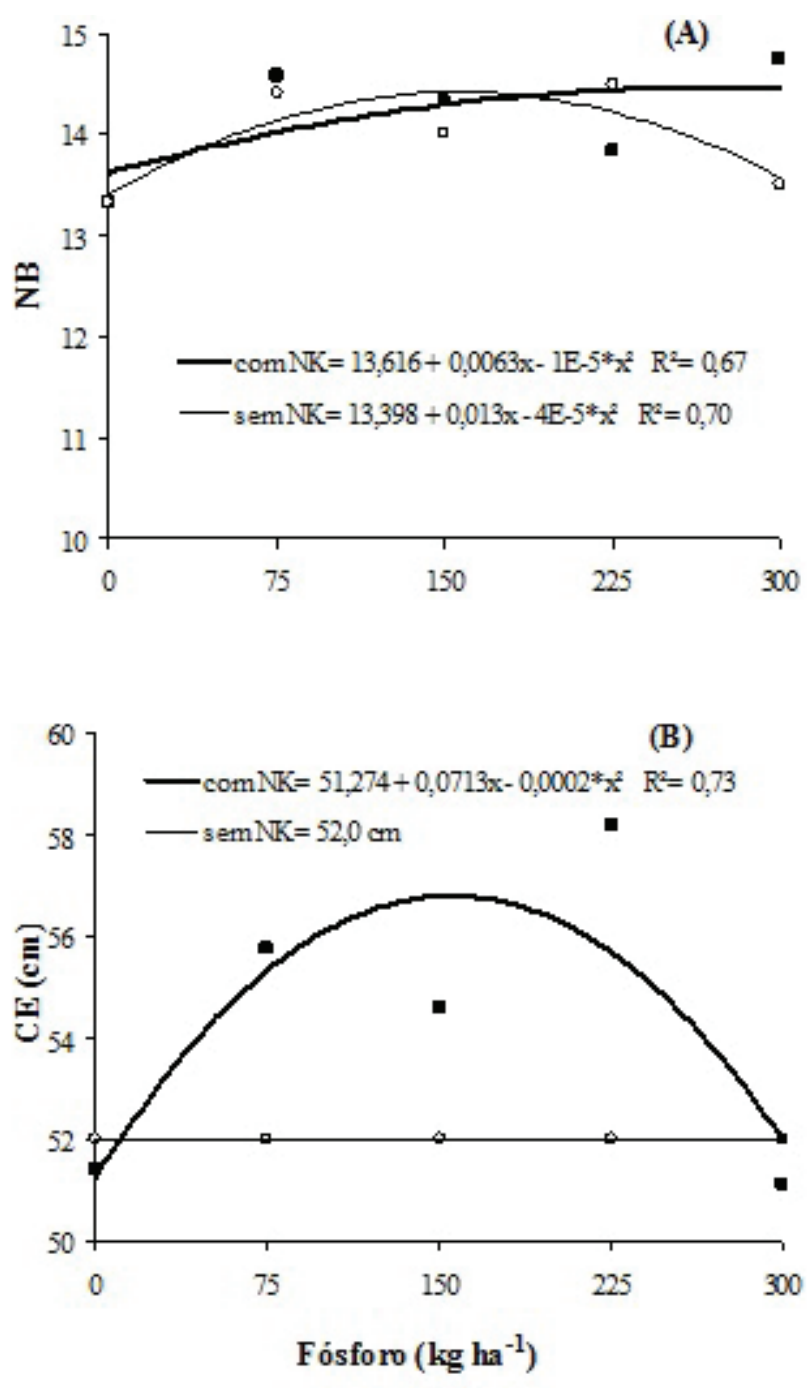

Figura 6. (A) Número de botões florais (NB); (B) comprimento da espiga floral (CE) de Gladiolus hortulanus L. cv. T704, na presença (com NK) e ausência (sem NK) da adubação nitogenadapotássica e das doses de fósforo estudadas.

Dourados-MS, UFGD, 2011.

Figure 6. (A) Number of flower buds (NB),

(B) length of floral spike (CE) Gladiolus hortulanus

L. cv. T704 in the presence ( to NK) and $a b$ sence (without NK) of nitrogen and potassium fertilization and phosphorus doses.

Dourados - MS, UFGD 2011.
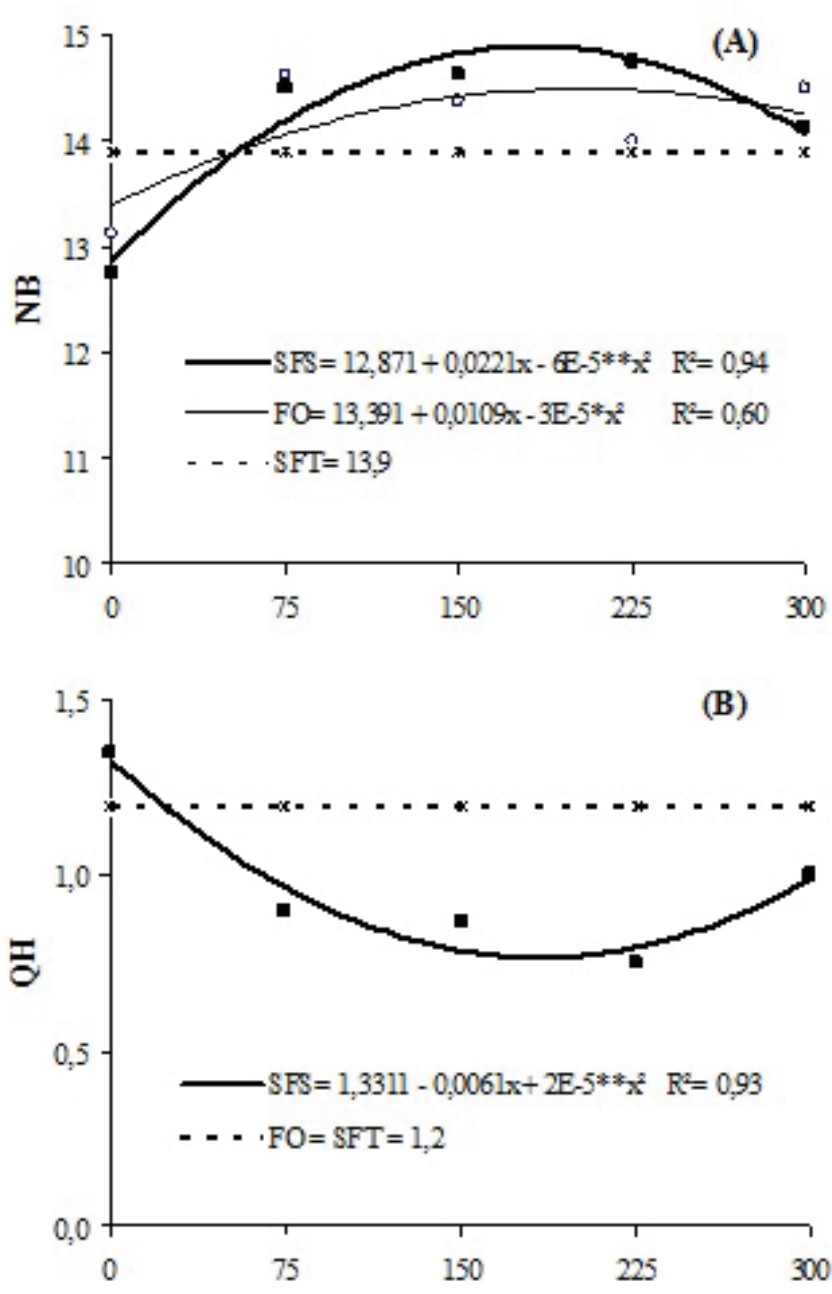

Fósforo $\left(\mathrm{kg} \mathrm{ha}^{-1}\right)$

Figura 7. (A) Número de botões florais (NB); (B) qualidade da haste floral $(\mathrm{QH})$ de Gladiolus hortulanus L. cv. T704, obtidos em função das fontes das doses de fósforo estudadas. Dourados-MS, UFGD, 2011.

$(\mathrm{FO}=$ farinha de osso; $\mathrm{SFS}=$ superfosfato simples; $\mathrm{SFT}=$ superfosfato triplo).

Figure 7. (A) Number of flower buds (NB), (B) flower stem quality $(\mathrm{QH})$ of Gladiolus hortulanus L. cv. T704, obtained as a function of the sources of phosphorus doses. Dourados MS, UFGD 2011.

$(\mathrm{FO}=$ bone meal $; \mathrm{SFS}=$ superphosphate, $\mathrm{TSP}=$ triple superphosphate) entretanto, plantas produzidas com NK foram mais altas que as produzidas sem NK, resultados estes que corroboram os relatos de Tombolato (2004) que atribui a diminuição do tamanho da haste floral à deficiência de potássio aliado ao fato que o nitrogênio é responsável pelo crescimento vegetal (TAIZ E ZEIGER, 2009). Independentemente da utilização ou não de NK, todas as hastes produzidas apresentaram espigas com comprimento superior a $40 \%$ da haste floral $(48,9 \%$ com $\mathrm{NK}$ e $48,5 \%$ sem NK), valor mínino exigido pelo Veiling Holambra (IBRAFLOR, 2012).

Para as demais variáveis, a adição de NK não influenciou os resultados observados, sendo registrados 8 botões coloridos, número total de botões por haste igual a 14,1 e comprimento da espiga floral de $53,1 \mathrm{~cm}$.

\section{CONCLUSÕES}

Para Gladiolus hortulanus L. cv. T704, a utilização da adubação NK é fundamental tanto para a durabilidade das suas flores quanto para a qualidade das hastes florais produzidas e as dosagens utilizadas neste trabalho foram suficientes para a obtenção da classe I de qualidade de gladíolos. 

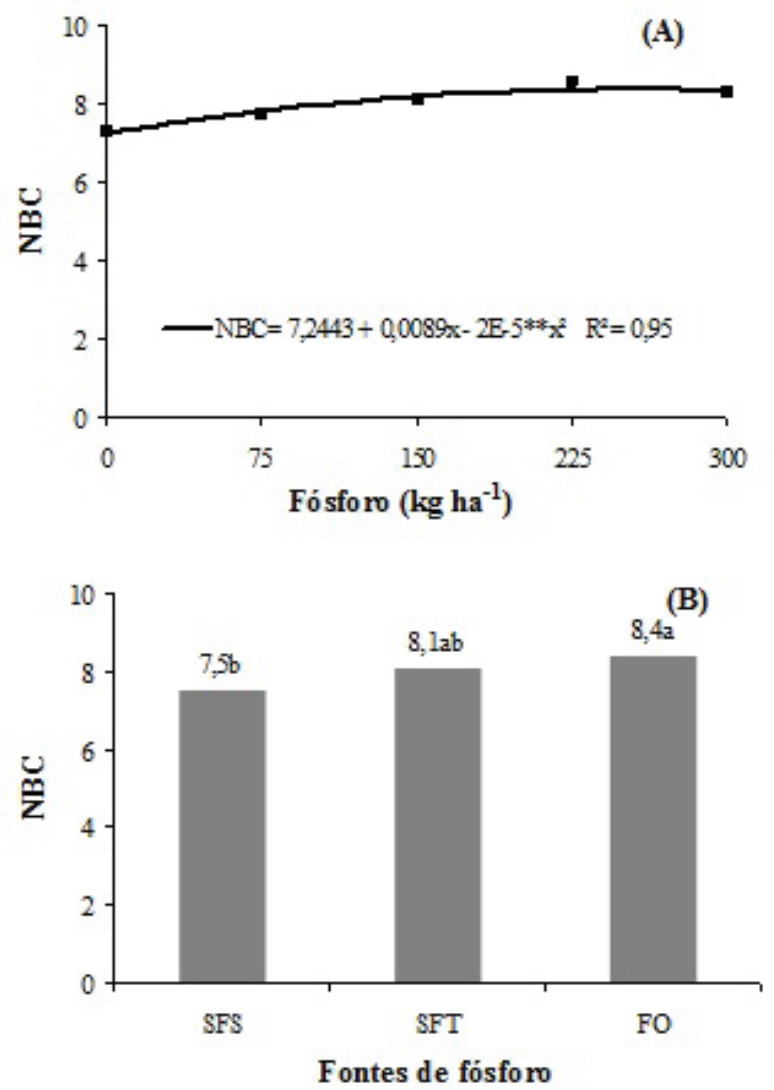

Figura 8. Número de botões coloridos de Gladiolus hortulanus L. cv. T704 observados após o período de refrigeração em função das doses (A) e das fontes (B) de fósforo estudadas. Dourados-MS, UFGD, 2011. $(\mathrm{FO}=$ farinha de osso; SFS= superfosfato simples; $\mathrm{SFT}=$ superfosfato triplo).

Figure 8. Number of colored buttons hortulanus Gladiolus L. cv. T704 observed after the cooling period as a function of the dose (A) and the source (B) of phosphorus. Dourados - MS, UFGD 2011.

( FO = bone meal ; SFS = superphosphate, TSP = triple superphosphate)

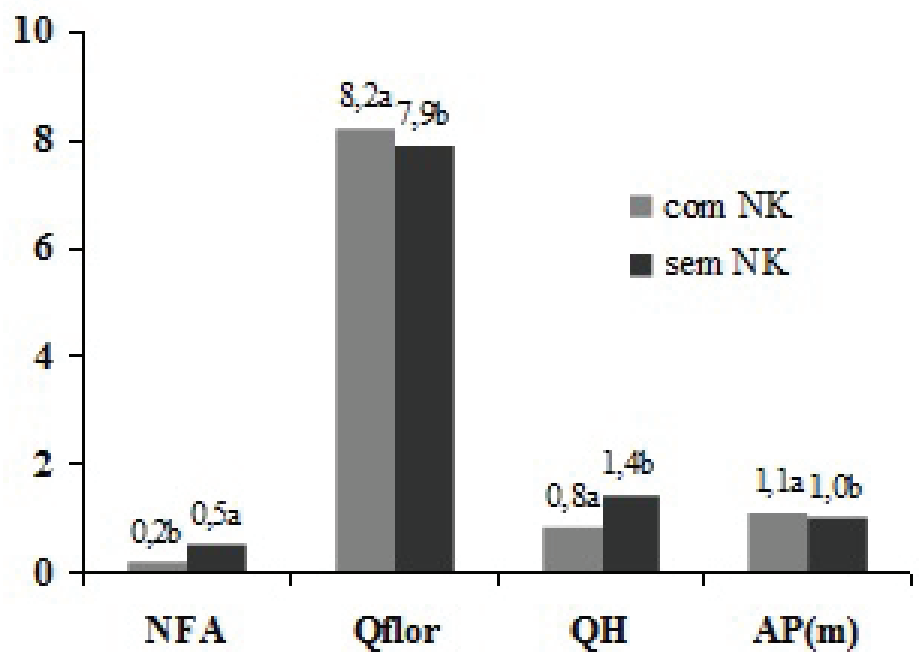

Figura 9. Número de flores abertas (NFA), qualidade da flor (QFlor), qualidade da haste floral (QH) e altura das plantas (AP) de Gladiolus hortulanus L. cv. T704 observados em função da adubação nitrogenada e potássica (NK). Dourados-MS, UFGD, 2011.

Figure 9. Number of open flowers (NFA), flower quality (QFlor), quality floral stem (QH) and plant height (PH) of Gladiolus hortulanus L. cv. T704 observed as a function of nitrogen and potassium (NK) fertilization. Dourados - MS , UFGD 2011 
A utilização de superfosfato triplo é mais eficiente quando se objetiva durabilidade das flores e, a de superfosfato simples, quando se objetiva qualidade das hastes florais.

Doses de fósforo entre 150 e $160 \mathrm{~kg} \mathrm{ha}^{-1}$ são suficientes para obtenção de durabilidade e qualidade das flores e hastes dessa cultivar.

\section{REFERÊNCIAS}

BONGERS, F.J.G. Informativo IBRAFLOR. Holambra, 2000.10p.

BORGES, E.M. Rendimento, qualidade e precocidade de gladíolo irrigado no Recôncavo Baiano. Cruz das Almas: Universidade Federal da Bahia, UFBA, 2005. 75p. Dissertação (Mestrado em Ciências Agrárias)

FELTRIM, E. Doses de calcário e potássio para o cultivo de gladíolos (Gladiolus grandiflorus var. Peter Pears), em Dourados/MS. Dourados: Universidade Federal da Grande Dourados, UFGD, 2009. 78p. Dissertação (Mestrado em Agronomia)

FERNANDES, M.S. Nutrição Mineral de Plantas. Viçosa: Sociedade Brasileira de Ciências do Solo, 2006. 432p.

FERREIRA, D.F. Sisvar: versão 5.3. Lavras: UFLA, DEX/ UFLA, 2010.

IBRAFLOR. Desenvolvimento recente da floricultura no Brasil. Instituto Brasileiro de Floricultura. Campinas, São Paulo, 2011.

JUNQUEIRA, A.H.; PEETZ, M.S. Analise conjuntural do mercado de flores e plantas ornamentais no Brasil: contexto \& perspectivas. Hórtica: Holambra. IBRAFLOR. Campinas, 2011. Disponível em: < http:/www.ibraflor.com/publicacoes/ vw.php?cod=161 $>$ Acesso em: 22 de jan. 2012.

KERBAUY, G.B. Fisiologia Vegetal. 2.ed. Rio de Janeiro: Guanabara Koogan, 2008. 431p.

KÖPPEN, W. Climatologia: con um estudio de los climas de la tierra. México: Fondo de Cultura Econômica, 1948. 479p.
MALAVOLTA, E. Manual de nutrição mineral de plantas. São Paulo: Agronômica Ceres, 2006. 638p.

MALAVOLTA, E.A.; VITTI, G.C.; OLIVEIRA, A.S. Avaliação do estado nutricional das plantas: princípios e aplicações. Piracicaba: Potafos, 1997. 308p.

MASCARENHAS, H.A.A.; TANAKA, R. T.; CARMELLO, Q. A. C.; GALLO, P. B.; AMBROSANO, G. M. B. Calcário e potássio para a cultura de soja. Scientia Agrícola, Piracicaba, v.57, n.3, p.445-449, 2000.

ROSA, Y.B.C.J; ROSA JUNIOR, E.J.; PEIXOTO, P.P.P.; ZARATE, N.A.H.; GANCEDO, M. Interação nitrogênio, calcário e gesso agrícola para o cultivo da planta ornamental gladíolo. Magistra, Cruz das Almas, v.21, n.4, p.311-20p, 2009.

RUPPENTHAL, V; CASTRO, A.M.C. Efeito do composto de lixo urbano na nutrição e produção de gladíolo. Revista Brasileira Ciência do Solo, Viçosa, v.29, n.1, p.145-50, 2005.

SILVA, L.R.; OLIVEIRA, M.D.M.; SILVA, S.M. Manejo póscolheita de hastes florais de gladíolos (Gladiolus grandiflorus L.) Acta Agronómica, Bogotá, v.57, n.2, p.129-35, 2008.

TAIZ, L.; ZEIGER, E. Fisiologia Vegetal. 3.ed. Porto Alegre: Artmed, 2009. 719p.

TOMBOLATO, A.F.C. Cultivo comercial de plantas ornamentais. Campinas: Instituto Agronômico, 2004. 211p.

ZUBAIR, M. Effect of potassium fertility levels on Gladiolus yield quality of cut flowers and corm production. Egyptian Academic Journal Biological Sciences, Abbasia, v.2, n.1, p.17-27, 2011.

ZUBAIR, M.; WAZIR F.K. Phosphorus affects production and quality of cut flowers of gladiolus cultivars in Peshawar. Paskitan Journal of Agricultural Research, Lahore, v.20, n.3-4, p.148-55, 2007. 